\title{
Deformation Behavior of Coarse-Grained Soil as an Embankment Filler under Cyclic Loading
}

\author{
Zhong-Ming He $\mathbb{D}^{1,2}$ Da Xiang $\mathbb{D}^{1},{ }^{2}$ Ya-Xin Liu, ${ }^{2}$ Qian-Feng Gao $\mathbb{D}^{2},{ }^{2}$ and Han-Bing Bian ${ }^{3}$ \\ ${ }^{1}$ Road Catastrophe Prevention and Traffic Safety Engineering Research Center of Ministry of Education, \\ Changsha University of Science \& Technology, Changsha 410114, China \\ ${ }^{2}$ School of Traffic \& Transportation Engineering, Changsha University of Science \& Technology, Changsha 410114, China \\ ${ }^{3}$ Laboratory of Civil Engineering and Geo-Environment, University of Lille, Lille 59000, France \\ Correspondence should be addressed to Qian-Feng Gao; qianfeng.gao@csust.edu.cn
}

Received 24 January 2020; Revised 15 July 2020; Accepted 31 July 2020; Published 17 August 2020

Academic Editor: Castorina S. Vieira

Copyright (c) 2020 Zhong-Ming He et al. This is an open access article distributed under the Creative Commons Attribution License, which permits unrestricted use, distribution, and reproduction in any medium, provided the original work is properly cited.

\begin{abstract}
This study aims to examine the deformation behavior and internal mechanism of coarse-grained soil as an embankment filler under cyclic loading. Numerical dynamic triaxial tests were performed on coarse-grained soil using the discrete element software PFC3D. The numerical model was verified by comparing the numerical results with the experimental data. Afterward, the changes in the porosity, force chain, and particle movement of coarse-grained soil samples were analyzed, and the mesoscopic deformation behavior of coarse-grained soil under cyclic loading was investigated. The research results show that with the increase of the deviatoric stress amplitude, moisture content, and loading frequency, the deformation of the soil increases and the ability to resist deformation decreases at the same loading cycles. Due to the inhomogeneous distribution of particles with different sizes, the velocity and displacement of the sample vary in different directions, exhibiting mesoscopic anisotropy. The contact force is relatively even in the downward direction while dispersed near the edge of the sample. This means that the particles at the bottom are less affected by loads and the internal evolution of soil samples conforms to its macroscopic deformation behavior during cyclic loading.
\end{abstract}

\section{Introduction}

Coarse-grained soil refers to the soil in which the grains are between $0.075 \mathrm{~mm}$ and $60 \mathrm{~mm}$ accounting for more than $50 \%$ of its total mass [1]. Because of the wide range of its gradation, coarse-grained soil has large porosity and strong permeability. After compaction, it has excellent engineering characteristics such as high compaction degree and high shear strength, so it is often used as an embankment filling material during highway construction. In engineering practice, the embankment filled with coarse-grained soil may present large settlements and local road sections even slide under seasonal rainfall and long-term vehicle loading. The vehicle load is a type of cyclic force since its direction and amplitude periodically change. To control the deformation and stability of the coarse-grained soil embankment, it is necessary to have a better understanding of the deformation behavior of coarse-grained soil during cyclic loading.

Traditional geotechnical tests are the most commonly used means to determine the mechanical properties and deformation behavior of coarse-grained soil. For instance, Trinh et al. [2] and Duong et al. [3] examined the effects of fines and water contents on the mechanical behavior of coarse-grained soil by large-scale triaxial tests. Wang et al. $[4,5]$ investigated the resilient modulus, damping ratio, and permanent deformation of coarse-grained soil by monotonic and cyclic triaxial tests. The behavior of coarse-grained soil was also studied based on the continuous medium assumption. Kong et al. [6] proposed an elastic-viscoplastic model for simulating the time-dependent behavior of coarse-grained soil in both shear and compression. Ren et al. 
[7] investigated the monotonic and cyclic characteristics of coarse-grained soil by soil-water coupling finite differencefinite element (FD-FE) deformation analyses. However, both the traditional geotechnical test and continuous medium analysis are not able to characterize the mesoscopic properties of coarse-grained soil. For this purpose, additional expensive techniques such as computed tomography and scanning electron microscopy should be incorporated into traditional tests $[8,9]$. The discrete element method (DEM) is a discontinuous numerical method, which solves the complex practical problems by simulating the motion of spheres and particles. This means that DEM allows the visualization of mesostructural evolution of materials. In essence, coarse-grained soil can be regarded as a typical granular material, particularly when its fines content is low. Thus, DEM is really appropriate to simulate coarse-grained soil.

In the literature, many scholars have examined the static mechanical behavior of coarse-grained soil based on DEM. Muhlhaus and Vardoulakis [10] studied the cause of the formation of shear bands and predicted the evolution of the shear band width in granular materials by biaxial tests using the DEM method. The authors reported that the problem of shear bands originated from the bifurcation characteristics of the soil. Ju et al. [11] investigated the strength, deformation, elastic modulus, failure process, and particle breakage of coarse-grained soil by DEM. The influence of different factors on the mechanical properties of granular materials has also received much attention. Jiang et al. $[12,13], \mathrm{Hu}$ et al. [14], and Shen et al. [15] examined the effects of different confining pressures, porosity, and particle rotations on the mechanical properties of granular materials using both laboratory triaxial tests and DEM simulations. Moreover, plenty of previous studies focused on the relationship between macromechanical responses and mesoscopic parameters. For example, Nardin and Schrefler [16] simulated the uniaxial compression and tensile tests on viscous materials by DEM and analyzed the correlation between macroscopic responses and mesoscopic parameters. Cho et al. [17] established the relationship between the macroscopic properties of a rock and the mesoscopic parameters of clumps. It was found that the stiffness ratio directly affects Poisson's ratio, and the uniaxial compressive strength depends on the number of particles in a clump. Park and Song [18] examined the effects of the geometrical features and the properties of a joint on its shear behavior by an extensive series of direct shear tests using the PFC3D code. They found that the friction coefficient was the most important factor governing the shear strength and dilation angle.

Some scholars also used the DEM method to analyze the dynamic responses of coarse-grained soil subjected to cyclic loads. For instance, Sazzad and Suzuki [19] investigated the micromechanical behavior of granular materials with different inherent anisotropies during cyclic loading using DEM. They found that the differences in inherent anisotropy obviously affect the stress-strain-dilative behavior of granular materials. O'Sullivan et al. [20] simulated the particlescale mechanics of the response of samples of uniform spheres to 50 cycles of loading with various strain amplitudes. The authors stated that there is a clear relation between the microscale parameters and the overall specimen response. Indraratna et al. [21] and Chen et al. [22] performed DEM simulations of the permanent deformation and degradation behavior of railway ballast under cyclic loading. They also explained the mechanism of particle breakage based on the evolution of micromechanical parameters such as the distribution of the contact force and bond force. Wang and Wang [23] investigated the liquefaction behavior and mesomechanism of gravelly soil under cyclic loading with constant strain amplitude. It was found that the liquefaction resistance of gravelly soil increases significantly with the increasing gravel content because of the growth in number of gravel-to-gravel contact. Jiang et al. [24] examined the microstructure and its evolution in granular soils subjected to cyclic loading using the DEM method. The research indicated that the evolutions of coordination number and contact fabric are highly dependent on the relative density and cyclic mode.

The research mentioned above focused on the mechanical properties and deformation behavior of different granular materials under various static or cyclic loads but dealt less with the dynamic behavior of coarse-grained soil subjected to vehicle loads. As a result, the previous results may not be applicable to coarse-grained soil as an embankment filler. The aim of this study is thus to examine the deformation behavior and internal mechanism of coarsegrained soil as an embankment filler under cyclic loading using the PFC3D software. The changes in the porosity, force chain, and particle movement of coarse-grained soil samples are examined, and the mesoscopic deformation behavior of coarse-grained soil under cyclic loading is analyzed. The results will provide a reference for embankment filling with coarse-grained soil in engineering practice.

\section{Materials and Samples}

The maximum dry density and optimum moisture content of the studied coarse-grained soil were measured by heavy compaction tests. The California bearing ratio (CBR) and resilient modulus were also determined using a CBR device and the loading plate method $[25,26]$. The main physical and mechanical properties of the studied soil are summarized in Table 1. The grain size distribution curve of this material is presented in Figure 1. It shows that the soil had a wide gradation with the fines fraction, sand fraction, and gravel fraction. According to the Chinese standard for soil classification (GB 50145-2007) [1], this material was classified as coarse-grained soil. The samples used for dynamic triaxial tests had a height of $200 \mathrm{~mm}$ and a diameter of $100 \mathrm{~mm}$. The maximum particle size should not exceed $1 / 5$ of the diameter of the sample so that the size effect could be controlled to the minimum $[27,28]$. This means that the maximum particle size of the soil sample should not exceed $20 \mathrm{~mm}$. For this reason, the particles of excess size were removed. The adjusted grading curve of the material for triaxial tests is also shown in Figure 1. 
TABLE 1: Basic physical and mechanical properties of coarse-grained soil.

\begin{tabular}{lccc}
\hline Maximum dry density $\left(\mathrm{g} / \mathrm{cm}^{3}\right)$ & Optimum moisture content $(\%)$ & California bearing ratio (\%) & Resilient modulus (MPa) \\
\hline 2.21 & 6.9 & 164 & 105.6 \\
\hline
\end{tabular}

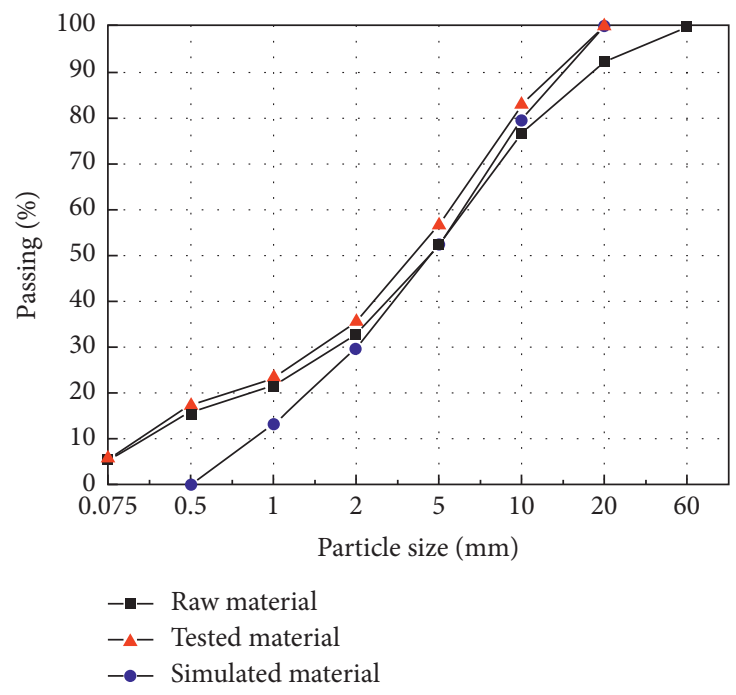

FIGURE 1: Grading curves of coarse-grained soil.

\section{Numerical Dynamic Triaxial Tests}

3.1. Establishment of the Model's Wall. The model boundary consists of a cylindrical wall and two loading plates (Figure 2(a)). The loading plates are modeled with clumps because of their advantage in applying dynamic stress [29-31]. The upper loading plate compresses the sample, and the bottom loading plate remains stationary during the simulation process. The cylindrical wall is modeled by a flexible particle membrane composed of particles of identical sizes (Figure 2(b)). The membrane particles are bonded following the contact bonding model to ensure the particles only transmit force but not moment. In order to prevent the particle membrane from being damaged or penetrated by soil particles during the loading process, the bond strength between membrane particles is set to a large value $(10 \mathrm{GPa})[32,33]$. The application of confining pressure is realized by applying equivalent concentrated forces to the membrane particles. During each step of the calculation, the equivalent concentrated forces applied on membrane particles are adjusted by a servo mechanism to maintain a constant confining pressure.

3.2. Generation of Soil Particles. The dynamic expansion method is used to generate soil particles. Following this method, small particles are generated first and then they are gradually enlarged to fill the internal space formed by the cylindrical wall and two loading plates.

However, if the particles are generated according to the actual grading curve (Figure 1), the number of particles will reach millions, which seriously affects the calculation efficiency; on the other hand, the computer's memory also does not allow calculating millions of particles. In such cases, it is usually recommended to properly adjust the grading curve [34-36]. In this study, the weighted average method proposed by Zhang et al. [37] is used to modify the particle group that is smaller than $1 \mathrm{~mm}$.

The weighted average radius of soil particles is calculated by [37]

$$
(r)=\sum R_{i} M_{i}=\sum W_{i}
$$

where $R_{i}$ is the average particle radius; $M_{i}$ is the content of particles smaller than a certain size; and $W_{i}$ is the weighted number of a certain particle size.

The calculation results are shown in Table 2. It shows that the weighted average radius of the soil particles is $2.768 \mathrm{~mm}$.

When the particle generation is performed based on the minimum radius and the ratio of the maximum radius to the minimum in DEM, the generation probability of the particle radius from the smallest to the largest is the same according to the random command. Thus, the minimum radius of the particles is fixed by the weighted average radius of the particles, and then the maximum radius of the particles is calculated. Therefore, the ratio of the maximum radius to the minimum radius is expressed by [37]

$$
\sum \frac{R_{i}}{R_{\min }+R_{\min } \gamma_{R_{\max / \min }}}=\sum W_{i}
$$

where $R_{\text {min }}$ is the minimum radius of soil particles and $\gamma_{R_{\text {maxim }}}$ is the ratio of the maximum radius to the minimum radius of soil particles.

In order to better simulate the indoor triaxial test at an acceptable speed, the minimum diameter of soil particles is fixed to $0.5 \mathrm{~mm}$. Thus, the ratio of the maximum radius to the minimum radius of soil particles is 39.265 . The modified grading curve used for simulations is presented in Figure 1. It shows that the grading curve modified by the weighted average 


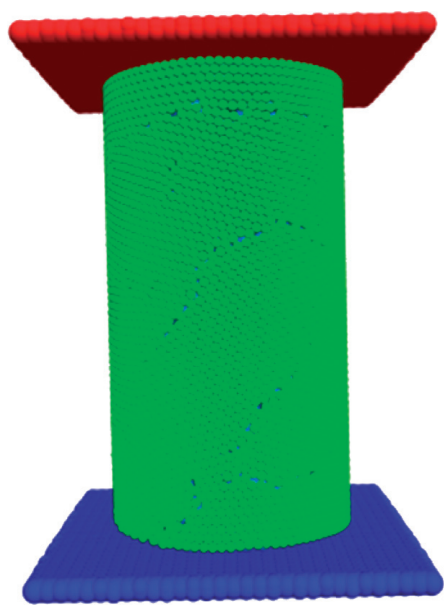

(a)

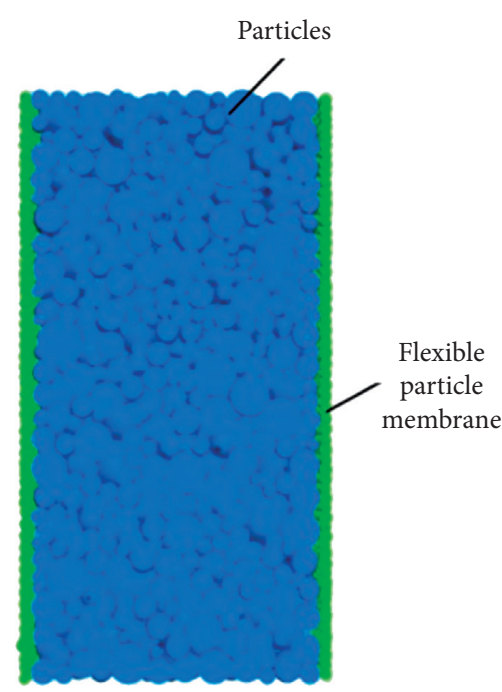

(b)

FIgURE 2: Schematic diagram of lateral wall and loading plates. (a) 3D view. (b) Flexible particle membrane.

TABLE 2: Weighted average radius of soil particles.

\begin{tabular}{lcccc}
\hline Grain size group $(\mathrm{mm})$ & Average particle size $(\mathrm{mm})$ & Average particle radius $R_{i}(\mathrm{~mm})$ & $\begin{array}{c}\text { Particle content } M_{i}(\%) \\
\text { Weighted number } W_{i} \\
(\mathrm{~mm})\end{array}$ \\
\hline $20-10$ & 15 & 7.5 & 17.1 & 1.282 \\
$10-5$ & 7.5 & 3.75 & 26.3 & 0.986 \\
$5-2$ & 3.5 & 1.75 & 21.2 & 0.371 \\
$2-1$ & 1.5 & 0.75 & 6.2 & 0.090 \\
$1-0.5$ & 0.75 & 0.375 & 5.4 & 0.023 \\
$0.5-0.25$ & 0.375 & 0.1875 & 6.1 & 0.010 \\
$0.25-0.075$ & 0.1625 & 0.08125 & 5.7 & 0.005 \\
$0.075-0$ & 0.0375 & 0.01875 & - & $\sum W_{i}=2.768$ \\
- & - & - & & \\
\hline
\end{tabular}

method is basically consistent with that used in laboratory tests. The modified grading curve not only effectively improves the calculation efficiency but also inherits the mesoscopic structural characteristics of coarse-grained soil. Figure 3 shows an example of the generated cylindrical sample.

3.3. Simulation Scheme. Table 3 shows the simulation scheme for dynamic triaxial tests, which is completely consistent with that employed in the laboratory tests. The moisture content of coarse-grained soil as an embankment filler usually falls between $5 \%$ and $10 \%$, so three moisture contents (i.e., $w=6.9 \%, 7.8 \%$, and $9.1 \%$ ) are used in the simulation; on the other hand, different deviatoric stress amplitudes (i.e., $\sigma_{0}=25 \mathrm{kPa}, 45 \mathrm{kPa}$, and $60 \mathrm{kPa}$ ) and loading frequencies (i.e., $f=0.5 \mathrm{~Hz}, 1.0 \mathrm{~Hz}$, and $3.0 \mathrm{~Hz}$ ) are selected considering the vehicle loading conditions [28, 38-42]. Because there are few fine particles in the coarse-grained soil, the bond between the particles is generally weak. This means that the moment is not able to be transferred between coarse soil particles, and thus the contact bonding model is used in the simulations $[43,44]$. The undetermined parameters involved in the numerical simulation include tangential contact stiffness $k_{s}$, normal contact stiffness $k_{n}$, interparticle friction coefficient $\mu$, density $\rho$, and porosity $n$.

3.4. Implementation of Dynamic Loading. The vehicle load is simulated by intermittent semisine waves, which is implemented by writing a cyclic loading code in Fish language. The expression of the deviatoric stress $\sigma_{t}$ at time $t$ is as follows:

$$
\sigma_{t}= \begin{cases}\frac{\sigma_{0}}{2}\left(1-\cos \frac{2 \pi}{t_{0}} t\right), & 0 \leq t \leq t_{0}, \\ 0, & t_{o} \leq t \leq T,\end{cases}
$$

where $\sigma_{0}$ is the maximum value of semisinusoidal stress; $t_{0}$ is the duration of each loading; and $T$ is the duration of one loading cycle.

During the cyclic loading process, the "history" command is used to monitor the deviatoric stress exerted by the loading plate and the axial permanent deformation of the sample. Figure 4 presents the curves of two loading schemes. The application of deviatoric stress is achieved by setting a velocity to the upper loading plate. The velocity is timely 


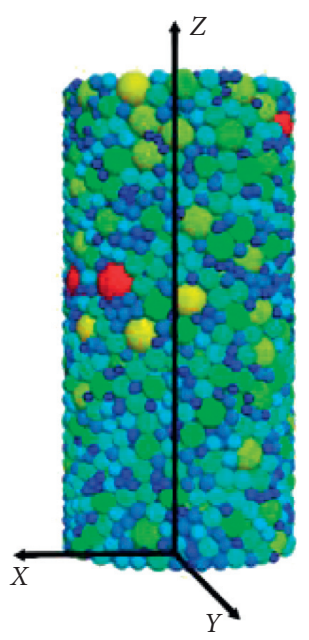

(a)

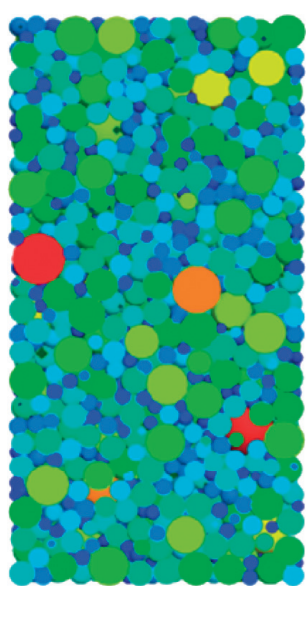

(b)

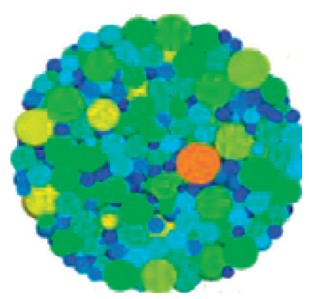

(c)

FIGURE 3: Numerical sample for dynamic triaxial test. (a) 3D view. (b) Vertical cross section. (c) Horizontal cross section.

TABLe 3: Simulation scheme for dynamic triaxial tests.

\begin{tabular}{lccccc}
\hline $\begin{array}{l}\text { Test } \\
\text { group }\end{array}$ & $\begin{array}{c}\text { Confining pressure } P \\
(\mathrm{kPa})\end{array}$ & $\begin{array}{c}\text { Loading frequency } f \\
(\mathrm{~Hz})\end{array}$ & $\begin{array}{c}\text { Moisture content } w \\
(\%)\end{array}$ & $\begin{array}{c}\text { Deviatoric stress amplitude } \sigma_{0} \\
(\mathrm{kPa})\end{array}$ & $\begin{array}{c}\text { Compaction degree } K_{\mathrm{c}} \\
(\%)\end{array}$ \\
\hline A1-A3 & & 0.5 & 6.9 & & \\
B1-B3 & 28 & 1.0 & 6.9 & $25,45,60$ & \\
C1-C3 & & 3.0 & 6.9 & \\
D1-D3 & & 1.0 & 7.8 & \\
E1-E3 & & 1.0 & 9.1 & \\
\hline
\end{tabular}

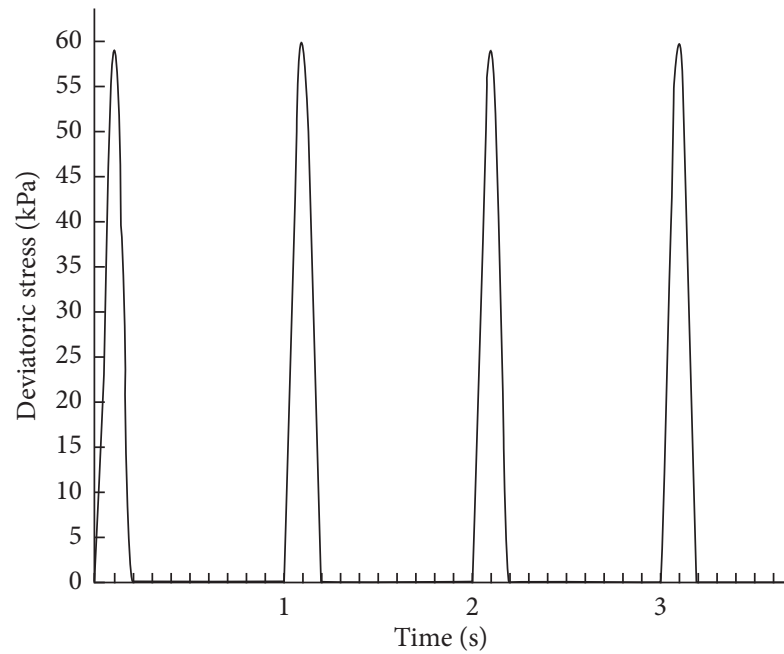

(a)

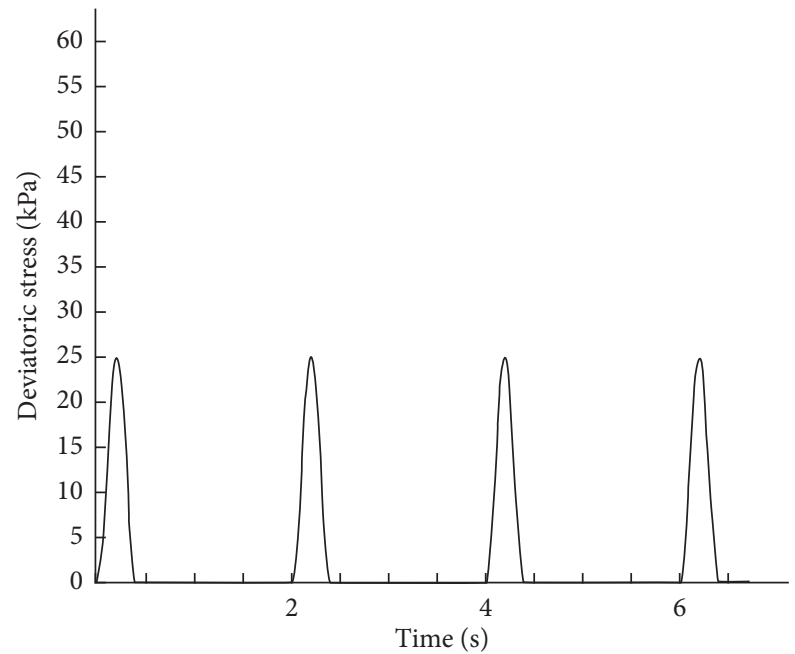

(b)

Figure 4: Cyclic loading curves for dynamic triaxial tests. (a) $\sigma_{0}=60 \mathrm{kPa}$ and $f=1 \mathrm{~Hz}$. (b) $\sigma_{0}=25 \mathrm{kPa}$ and $f=0.5 \mathrm{~Hz}$.

adjusted considering the gap between the calculated stress and the target value.

3.5. Calibration of Mesoscopic Parameters. The calibration of mesoscopic parameters is critical since it greatly affects the reliability of the DEM simulation. To date, there is no direct means to predetermine the mesoscopic parameters. The commonly used calibration method is to compare numerical data and test results until the difference between them is smaller than a certain value. The calibration procedure used in this study is shown in Figure 5. 


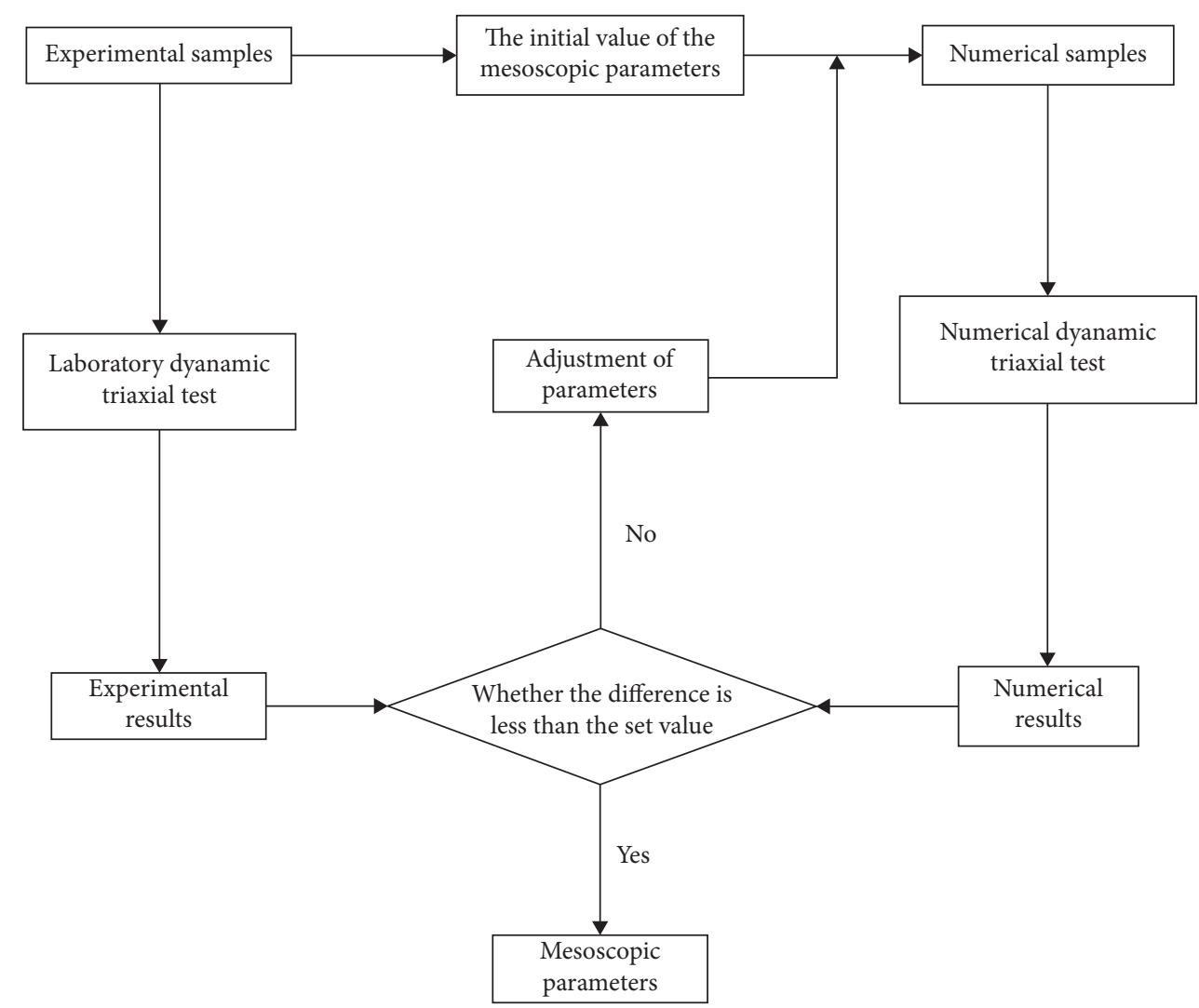

Figure 5: Calibration process of mesoscopic parameters of coarse-grained soil.

To determine the mesoscopic parameters, repeated tentative calculations are conducted following the procedure shown in Figure 5. Firstly, according to the characteristics of PFC3D software and triaxial test, the porosity $n$ of the numerical model is determined, and then the particle contact stiffnesses $k_{n}$ and $k_{s}$ are calibrated so that the simulated permanent deformation curve is approximately the same as the test curve, and then the stiffness of flexible particle membrane $k_{n}$ and $k_{s}$ is determined; finally, repeatedly adjust the interparticle friction coefficient $\mu$ and linear bond strength $c b \_n$ and $c b \_s$ until the shapes, slopes, and peak values of the numerical curves are broadly consistent with the experimental ones, and the difference between the test results and the numerical simulation results is controlled within $20 \%$. The calibrated mesoscopic parameters are summarized in Table 4.

For coarse-grained soil, the bond strength between particles often varies with the change of moisture content, so the bond strength can be determined based on the established relationship between bond strength and moisture content. Nevertheless, it is not able to directly define the moisture content in DEM. Thus, the yield stress is used as an intermediate variable to derive the relationship between the moisture content and the particle bond strength $[45,46]$.

\section{Analysis of Calculation Results}

4.1. Comparative Analysis of Numerical and Experimental Results. According to the calibrated mesoscopic parameters of the model, numerical dynamic triaxial tests are conducted. The obtained numerical results are compared with the experimental data, as shown in Figure 6.

Figure 6(a) presents that the axial permanent deformation of the sample increases rapidly during the first 1000 loading cycles, reaching $80 \%$ of the final permanent deformation, and then the deformation slowly increases and gradually tends to be a fixed value. When the deviatoric stress amplitude is small (e.g., $25 \mathrm{kPa}$ ), the cumulative curve of the axial permanent deformation tends to be flat after the number of loading cycles reach 1000; at the same time, as the deviatoric stress amplitude increases, the axial permanent deformation increases accordingly. It is deduced that the embankment soil may be damaged under excessive deviatoric stress even if the duration of cyclic loading is short. Therefore, to reduce the permanent deformation of the embankment filled with coarse-grained soil, the internal stress of the granular layer should be considered when designing the embankment. During the road operation period, heavy-duty vehicles should be restricted to reduce the stress transmitted to the embankment and thus reduce the permanent deformation of the embankment.

From Figure 6(b), it can be seen that the axial permanent deformation increases significantly with the increase of the moisture content, but the axial deformation rate gradually decreases with the number of loading cycles. When the moisture content is $6.9 \%$, the axial permanent deformation of the sample after 10,000 loading cycles is $0.06 \%$, and when the moisture content increases from $6.9 \%$ to $9.1 \%$, the axial permanent deformation increases up to $0.15 \%$ after 10,000 
TABLE 4: Calibrated mesoscopic parameters.

\begin{tabular}{lcccc}
\hline Type & $\begin{array}{c}\text { Tangential contact stiffness } \\
k_{s}(\mathrm{~N} / \mathrm{m})\end{array}$ & Normal contact stiffness $k_{n}(\mathrm{~N} / \mathrm{m})$ & $\begin{array}{l}\text { Interparticle friction coefficient } \mu \\
\left(\mathrm{kg} / \mathrm{m}^{3}\right)\end{array}$ & $\begin{array}{c}\text { Density } \rho \\
\text { Porosity } n\end{array}$ \\
\hline Soil particles & 200.83 & 100.36 & 0.4 & 2650 \\
\hline Wall particles & $1 \times 10^{8}$ & $1 \times 10^{8}$ & - & 0.35 \\
\hline
\end{tabular}

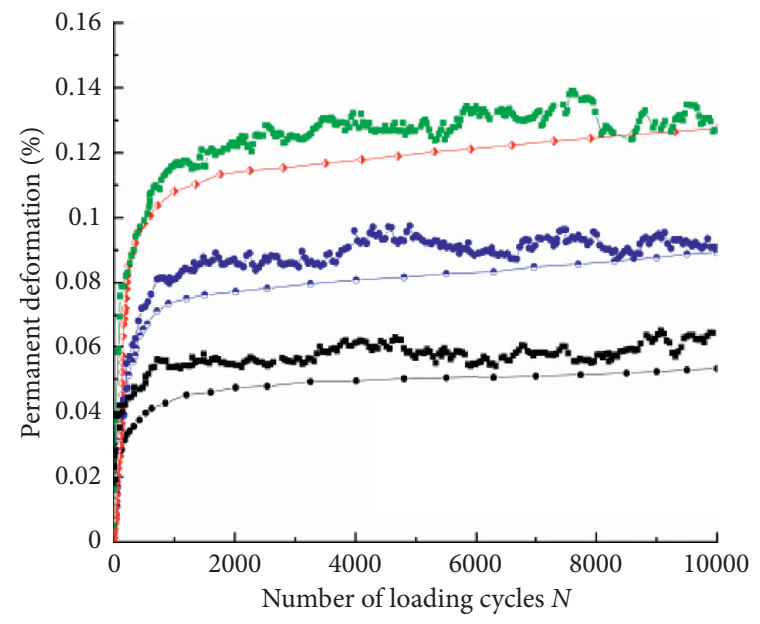

Experimental data $\begin{array}{lll}\rightarrow 25 \mathrm{kPa} & \rightarrow 40 \mathrm{kPa} & \rightarrow 60 \mathrm{kPa} \\ \text { Numerical data } & & \\ \rightarrow-25 \mathrm{kPa} & \rightarrow 40 \mathrm{kPa} & \rightarrow 60 \mathrm{kPa}\end{array}$

(a)

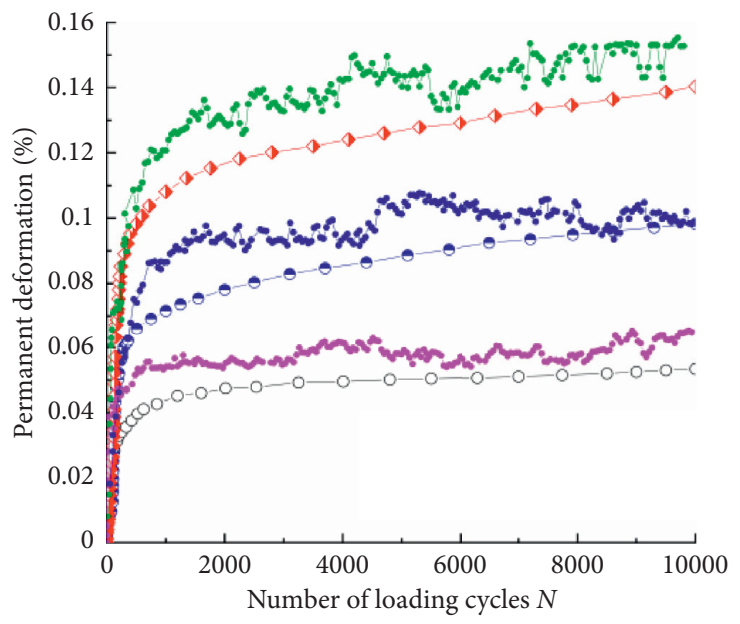

Experimental data

$\begin{array}{lll}-6.9 \% & -7.8 \% & -\end{array}$

Numerical data

$\longrightarrow 6.9 \%$

$\longrightarrow 7.8 \%$

$\longrightarrow \quad 9.1 \%$

(b)

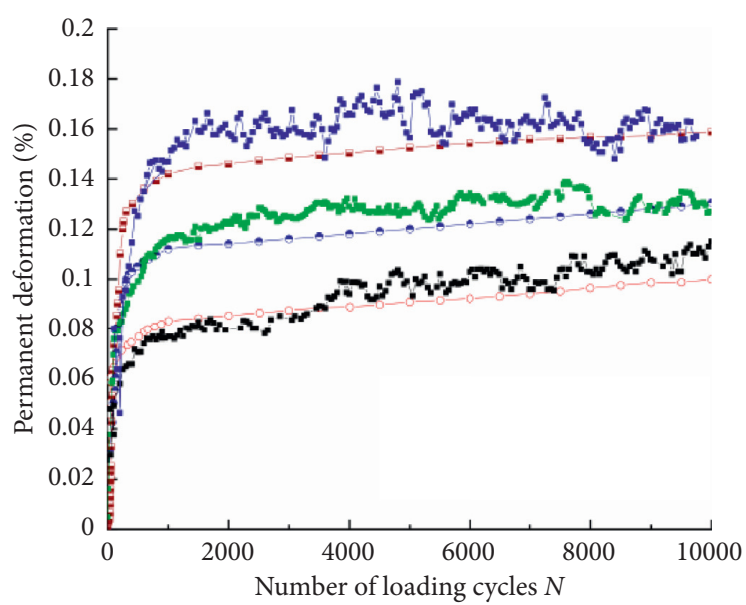

Experimental data

$\begin{array}{lll}\multimap-0.5 \mathrm{~Hz} & \rightarrow 1 \mathrm{~Hz} & \square-3 \mathrm{~Hz} \\ \text { Numerical data } & & \\ \rightarrow-0.5 \mathrm{~Hz} & \rightarrow 1 \mathrm{~Hz} & \rightarrow 3 \mathrm{~Hz}\end{array}$

(c)

FIgure 6: Permanent deformations of samples in laboratory tests and numerical simulations. (a) At different deviatoric stress amplitudes $(w=6.9 \%$ and $f=1 \mathrm{~Hz})$. (b) At different moisture contents $\left(\sigma_{0}=25 \mathrm{kPa}\right.$ and $\left.f=1 \mathrm{~Hz}\right)$. (c) At different loading frequencies $\left(\sigma_{0}=60 \mathrm{kPa}\right.$ and $w=6.9 \%)$.

loading cycles. The results show that the moisture content has a significant effect on the deformation of coarse-grained soil. When the moisture content is greater than the optimum moisture content (i.e., 6.9\%), water presents as a water film in the soil, which plays a certain role in lubricating the soil particles. With the increase of moisture content, the soil's 
lubricating effect is enhanced under long-term cyclic loading, and the friction between particles is reduced. During the entire shearing process, the work required to overcome the friction between particles is less than the work performed at the optimum moisture content, resulting in increased axial permanent deformation.

It is observed from Figure 6(c) that the axial permanent deformation increases significantly with the increase of loading frequency. The internal structure of the soil is changed by external forces in the loading phase and partially recovered in the unloading phase. Obviously, the recovery of the changed structure needs a certain period of time. However, the time for the soil structure to recover is closely related to the loading frequency. Generally, the larger the loading frequency is, the shorter the time for soil recovery is. When a large deviatoric stress is applied on the embankment, the permanent deformation of the embankment increases with the increase of the vehicle speed at the same number of loading cycles. Therefore, the vehicle speed should be limited to reduce the impact of loading frequency on the embankment deformation.

From Figures 6(a)-6(c), one can note that the laboratory experimental results and the numerical data have a good consistency on the whole. For instance, when the deviatoric stress amplitude is $25 \mathrm{kPa}$, the moisture content is $6.9 \%$ and the loading frequency is $1 \mathrm{~Hz}$, and there is a difference of about $15 \%$ in the early deformation stage (0-1000th cycles). As the number of loading cycles increases, the deformation difference becomes smaller and smaller, and the final deformation difference is less than $10 \%$. The results indicate the rationality of the model establishment, particle size modification, and mesoscopic parameters. The numerical data are slightly larger than the experimental values. This is probably related to the difference in particle shapes. In this study, sphere particles are used for test simulations, and the influence of particle angularity on deformation of the material is ignored. Although the friction and bonding model has been given to the particles, the friction and bonding between particles cannot be accurately represented.

4.2. Analysis of Internal Force Chains. Particle contact will form contact force chains throughout the entire model. The number of weak contact force chains is much more and is evenly distributed among the particles; the strong contact force chains are fewer and nonuniformly formed between the particles, but they support the load of the entire particle system.

Figure 7 shows the contact force chain diagram of discrete element samples with a moisture content of $6.9 \%$ under a loading frequency of $1 \mathrm{~Hz}$ and different deviatoric stress amplitudes after 1000 cyclic loads. The black chain represents compression, the red chain represents tension, and the thickness of the chain represents the magnitude of the contact force between the particles. From the figure, the contact force chain distribution of the discrete element sample can be seen intuitively. At the same moisture content and loading frequency, as the deviatoric stress amplitude increases, the force chain distribution gradually changes from sparse to dense, and the force chain changes from thin to thick. This indicates that the number of stressed skeleton particles increases and the contact force between the particles gradually increases.

Figure 8 shows the contact force chains in samples with three different moisture contents under a deviatoric stress amplitude of $60 \mathrm{kPa}$ and a loading frequency of $1 \mathrm{~Hz}$ after 1000 cyclic loads. It is noted that with the increase of the moisture content, the axial permanent deformation increases at the macroscopic level. In this case, the distribution of the compressive force chain changes from dense to sparse and the tensile force chain gradually increases at the mesoscopic level. Meanwhile, the number of stressed skeleton particles gradually decreases, and the deformation of the sample gradually increases, which is consistent with the macromechanical properties.

Figure 9 illustrates the force chains in samples with a moisture content of $6.9 \%$ under three different loading frequencies and a deviatoric stress amplitude of $60 \mathrm{kPa}$ after 1000 cyclic loads. With the increase of the loading frequency, the macroscopic performance is that the axial permanent deformation increases; moreover, the tensile force chain is less and more concentrated on the upper and lower surfaces at the mesoscopic level. And as the loading frequency increases, the tensile force chain gradually increases and moves closer to the middle of the sample, but the number of tensile force chains is less than the number of compressive force chains. As a result, no shear failure occurs to the sample, which is consistent with the macromechanical behavior.

4.3. Law of Particle Motion. The position of particles inside the embankment constantly changes during road operations. In this section, the particle velocity and displacement track in different directions at the end of the initial loading stage (i.e., 1000th cycle) are analyzed. This simulation is performed with the sample with a moisture content of $6.9 \%$ under a deviatoric stress amplitude of $60 \mathrm{kPa}$ and a loading frequency of $1 \mathrm{~Hz}$.

In Figures $10(\mathrm{a})-10(\mathrm{c})$, the red area represents the positive velocity and the blue area represents the negative velocity. The darker the color of the particle, the greater the absolute value of the velocity. Figures 10(a) and 10(b) present that the absolute value of the velocity is increasing from the center axis of the test sample to the edge of the test sample, indicating that the particles have a velocity of moving outwards during the test. Figure 10(c) presents that the particles have a downward moving velocity under cyclic loading, and the velocity gradually decreases with the decrease of the height. Figure 10(d) shows the displacement track of particles. The arrow in the figure indicates the direction of particle movement. It is observed that the particles have a tendency to move outward under cyclic loading, which is consistent with the results shown in Figures 10(a)10(c). According to Figure 10, the velocity and displacement in the three directions of the sample are not uniformly distributed but exhibit obvious anisotropy, which may also 


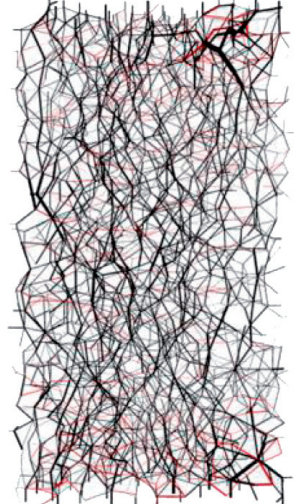

(a)

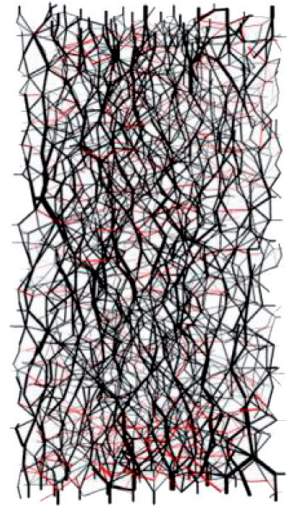

(b)

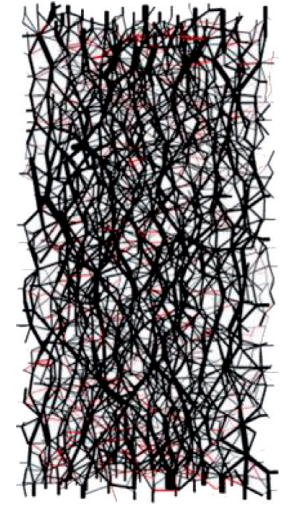

(c)

Figure 7: Contact force chains of discrete element samples at $w=6.9 \%$ and $f=1 \mathrm{~Hz}$ affected by deviatoric stress amplitude. (a) $\sigma_{0}=25 \mathrm{kPa}$. (b) $\sigma_{0}=45 \mathrm{kPa}$. (c) $\sigma_{0}=60 \mathrm{kPa}$.

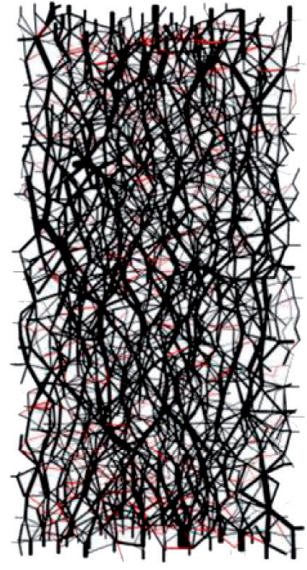

(a)

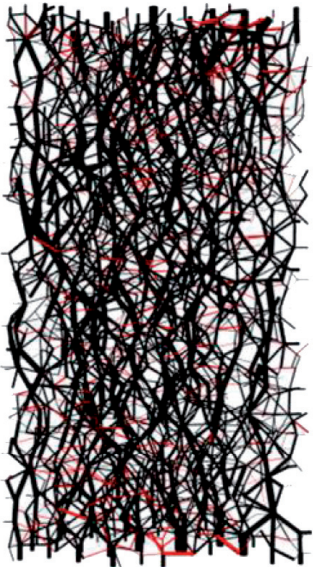

(b)

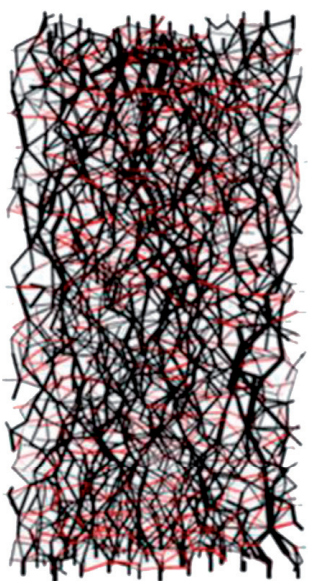

(c)

Figure 8: Contact force chains of discrete element samples with different moisture contents under $\sigma_{0}=60 \mathrm{kPa}$ and $f=$ of $1 \mathrm{~Hz}$. (a) $w=6.9 \%$. (b) $w=7.8 \%$. (c) $w=9.1 \%$.

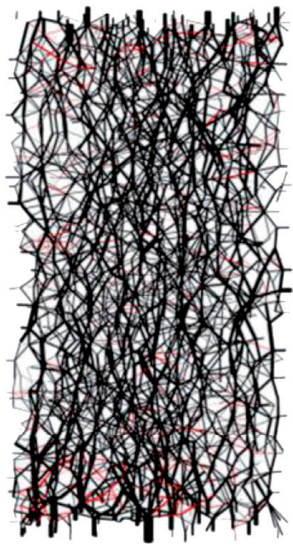

(a)

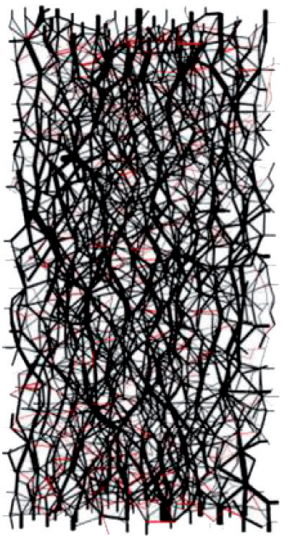

(b)

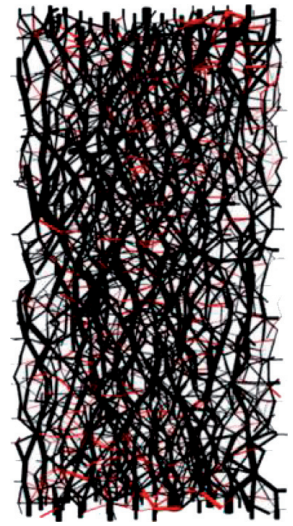

(c)

FIGURE 9: Contact force chains of discrete element samples with $w=6.9 \%$ under different loading frequencies and $\sigma_{0}=60 \mathrm{kPa}$. (a) $f=0.5 \mathrm{~Hz}$. (b) $f=1 \mathrm{~Hz}$. (c) $f=3 \mathrm{~Hz}$. 


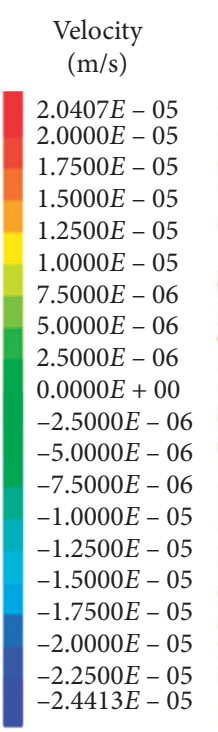

$$
\begin{gathered}
\text { Velocity } \\
(\mathrm{m} / \mathrm{s})
\end{gathered}
$$$$
\begin{aligned}
& 5.0805 E-02 \\
& 0.0000 E+00 \\
& -1.0000 E+00 \\
& -2.0000 E+00 \\
& -3.0000 E+00 \\
& -4.0000 E+00 \\
& -5.0000 E+00 \\
& -6.0000 E+00 \\
& -7.0000 E+00 \\
& -8.0000 E+00 \\
& -9.0000 E+00 \\
& -1.0000 E+01 \\
& -1.1000 E+01 \\
& -1.1078 E+01
\end{aligned}
$$

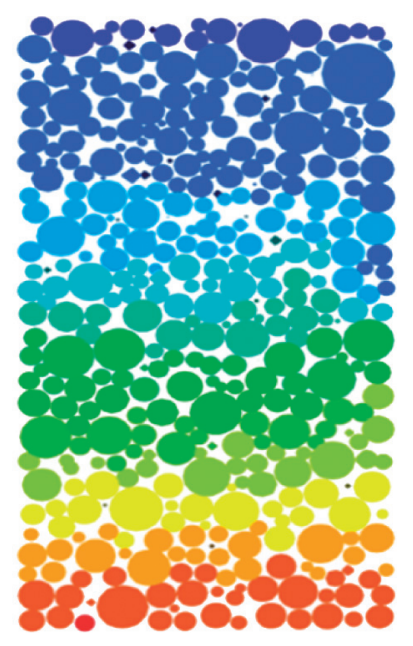

(c)

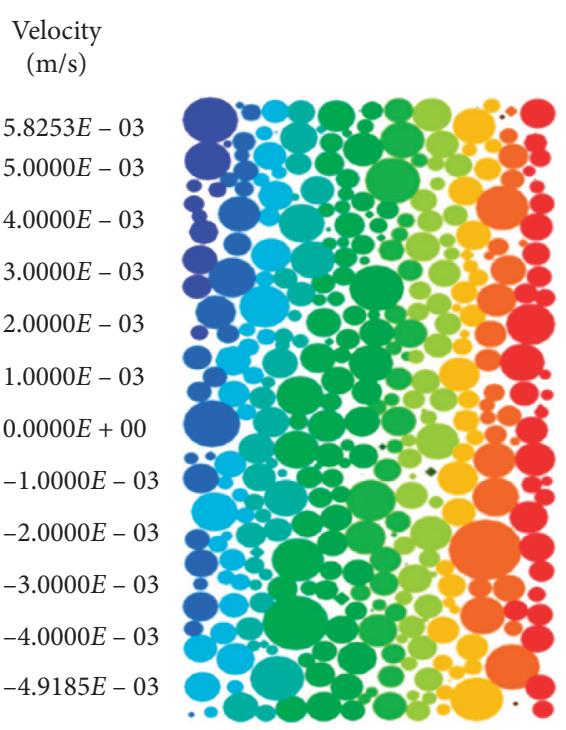

(b)

$$
\begin{gathered}
\text { Velocity } \\
(\mathrm{m} / \mathrm{s})
\end{gathered}
$$
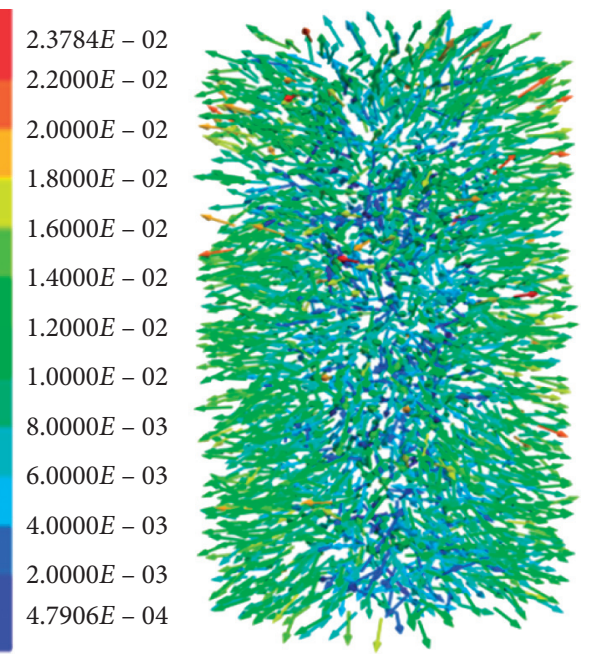

(d)

Figure 10: Internal velocity and displacement track of soil particles. (a) Velocity in $X$ axis. (b) Velocity in $Y$ axis. (c) Velocity in $Z$ axis. (d) Particle displacement track.

be related to the uneven spatial distribution of particles with different particle sizes in addition to the loading anisotropy.

4.4. Variation of Porosity. In the PFC3D software, the porosity is defined as the ratio of the volume of pores in a measurement circle to the volume of the measurement circle. The change of the porosity reflects the compactness of the sample during the test. The smaller the porosity of the sample, the denser the sample. The conventional test cannot directly measure the change of the porosity during the test, and the indirect method is easy to cause disturbance to the sample and affect the test results. The PFC3D software can monitor the change of internal porosity in real time, which plays a positive role in analyzing the permanent deformation mechanism of coarse-grained soil under cyclic loading. Five measurement circles with radius of $5 \mathrm{~mm}$ are created (Figure 11). As an example, the change of porosity of the sample in scheme $\mathrm{E} 3\left(\sigma_{0}=60 \mathrm{kPa}, w=9.1 \%\right.$, and $\left.f=1 \mathrm{~Hz}\right)$ is illustrated in Figure 12.

It is noted that as the cyclic loading progresses, the porosity decreases continuously. The variation of porosity at the measurement circles 4 and 5 is similar. The porosity has the smallest change and fluctuates around $22 \%$ at the measurement circle 3. This is because the cyclic load is applied to the sample via the upper loading plate, and the bottom of the sample is obviously less affected by the load. Under the action of cyclic loading, the coarse-grained soil is continuously compacted, thus reducing the porosity. 


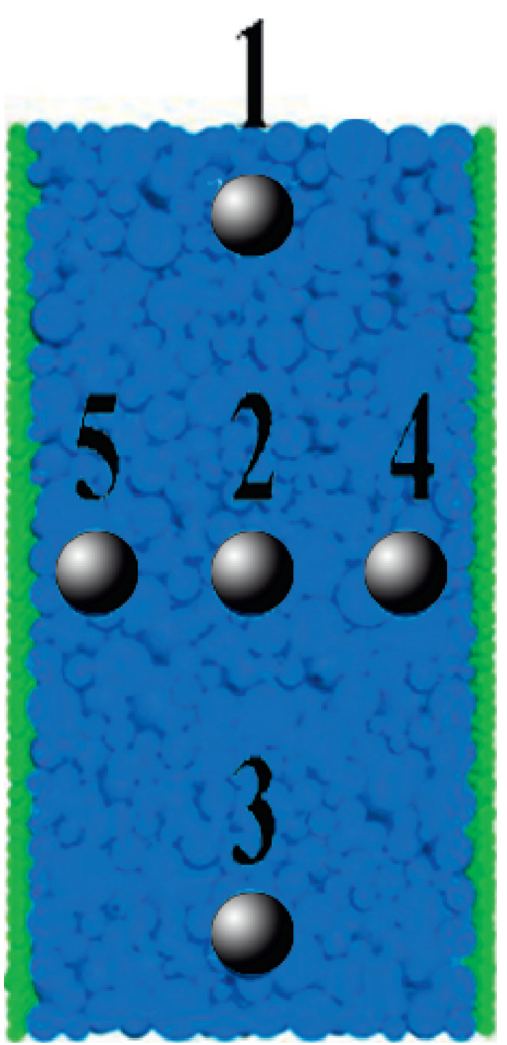

FIGURE 11: Schematic diagram of measurement circles.

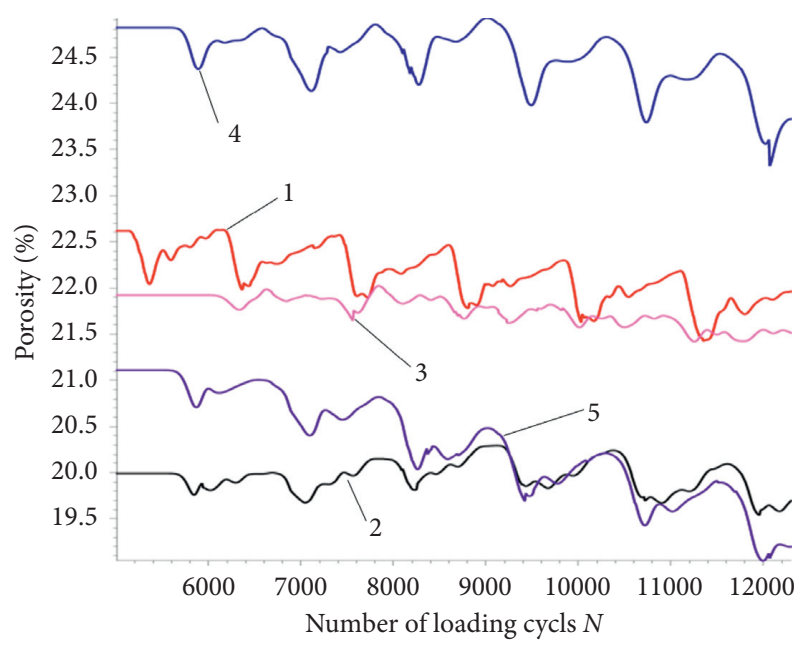

FigURE 12: Variation of porosity at different measurement circles.

\section{Conclusion}

(1) The permanent deformation of coarse-grained soil increases rapidly during the first 1000 loading cycles, reaching $80 \%$ of the final permanent deformation value, after which the deformation slowly increases and gradually approaches a fixed value. Also, with the increase of deviatoric stress amplitude, the moisture content, and loading frequency, the deformation of the sample at the same number of loading cycles increases and the ability to resist deformation decreases in different degrees.

(2) Under the same moisture content and loading frequency, with the increase of the deviatoric stress amplitude, the force chain distribution gradually changes from sparse to dense; meanwhile, the force chain changes from thin to thick, the number of stressed skeleton particles increases, and the contact force between the particles gradually increases. Under the same deviatoric stress amplitude and loading frequency, with the increase of moisture content, the axial permanent deformation increases, the distribution of the compressive force chain changes from dense to sparse, and the tensile force chain gradually increases; thus, the number of stressed skeleton particles gradually decreases, and the deformation of the sample gradually increases. Under the same moisture content and deviatoric stress amplitude, the axial permanent deformation increases with the increase of the loading frequency and the tensile force chain gradually increases and moves closer to the middle of the sample, but the number of tensile force chains is less than the number of compressive force chains, and no shear failure occurs to the sample, which is consistent with the macromechanical behavior.

(3) The velocity and displacement in the three directions of the sample are not uniformly distributed, exhibiting obvious anisotropy. This may be related to the uneven spatial distribution of particles with different particle sizes in addition to the loading anisotropy. The contact force is relatively even in the downward direction while dispersed near the edge of the sample. Meanwhile, the bottom of the sample is less affected by the cyclic load. The coarse-grained soil is continuously compacted under cyclic loading, thus reducing the porosity.

(4) The mechanical characteristics and mesoscopic deformation of coarse-grained soil affected by deviatoric stress amplitudes, moisture contents, and loading frequencies were analyzed in this study. However, the environment of a practical embankment is much more complicated. As a matter of fact, the drying-wetting cycles and the temperature change will also affect the service performance of the embankment filled with coarse-grained soil. Therefore, in the follow-up studies, the effects of various factors on the mechanical properties of the coarse-grained soil as embankment filler should be comprehensively considered.

\section{Data Availability}

The data used to support the finding of this study are available from the corresponding author upon request. 


\section{Conflicts of Interest}

The authors declare that there are no conflicts of interest regarding the publication of this paper.

\section{Acknowledgments}

This research was financially supported by the National Natural Science Foundation of China (grant nos. 51978084 and 51678073), the Natural Science Foundation of Hunan Province (grant no. 2020JJ4605), and the "Double First Class" International Cooperation and Development Project of Scientific Research by Changsha University of Science \& Technology (grant no. 2019IC13).

\section{References}

[1] GB 50145-2007, Standard for Engineering Classification of Soil, China Planning Press, Beijing, China, 2007, in Chinese.

[2] V. N. Trinh, A. M. Tang, Y.-J. Cui et al., "Mechanical characterisation of the fouled ballast in ancient railway track substructure by large-scale triaxial tests," Soils and Foundations, vol. 52, no. 3, pp. 511-523, 2012.

[3] T. V. Duong, A. M. Tang, Y.-J. Cui et al., "Effects of fines and water contents on the mechanical behavior of interlayer soil in ancient railway sub-structure," Soils and Foundations, vol. 53, no. 6, pp. 868-878, 2013.

[4] H. L. Wang, Y. J. Cui, F. Lamas-Lopez et al., "Permanent deformation of track-bed materials at various inclusion contents under large number of loading cycles," Journal of Geotechnical and Geoenvironmental Engineering, vol. 144, no. 8, Article ID 04018044, 2018.

[5] H.-L. Wang, Y.-J. Cui, F. Lamas-Lopez et al., "Effects of inclusion contents on resilient modulus and damping ratio of unsaturated track-bed materials," Canadian Geotechnical Journal, vol. 54, no. 12, pp. 1672-1681, 2017.

[6] Y. Kong, M. Xu, and E. Song, "An elastic-viscoplastic doubleyield-surface model for coarse-grained soils considering particle breakage," Computers and Geotechnics, vol. 85, pp. 59-70, 2017.

[7] F. Ren, J. He, F. Zhang, G. Wang, and Q. Zhao, "Numerical investigation of the influence of non-uniform factors on the monotonic/cyclic behaviour of coarse-grained soil," Computers and Geotechnics, vol. 103, pp. 115-137, 2018.

[8] Q.-F. Gao, Z.-N. Shi, J.-T. Luo, and J. Liu, "Microstructural insight into permeability and water retention property of compacted binary silty clay," Journal of Central South University, vol. 27, no. 7, pp. 2068-2081, 2020.

[9] Q. F. Gao, M. Jrad, M. Hattab et al., "Pore morphology, porosity and pore size distribution in kaolinitic remoulded clays under triaxial loading," International Journal of Geomechanics, vol. 20, no. 6, Article ID 04020057, 2020.

[10] H. B. Muhlhaus and I. Vardoulakis, "The thickness of shear bands in granular materials," Geotechnique, vol. 37, no. 3, pp. 271-283, 2017.

[11] Y. Ju, H. Sun, M. Xing, X. Wang, and J. Zheng, "Numerical analysis of the failure process of soil-rock mixtures through computed tomography and PFC3D models," International Journal of Coal Science \& Technology, vol. 5, no. 2, pp. 126$141,2018$.

[12] M. Jiang, F. Zhang, H. Hu, Y. Cui, and J. Peng, "Structural characterization of natural loess and remolded loess under triaxial tests," Engineering Geology, vol. 181, pp. 249-260, 2014.

[13] M. Jiang, H. Zhu, and X. Li, "Strain localization analyses of idealized sands in biaxial tests by distinct element method," Frontiers of Architecture and Civil Engineering in China, vol. 4, no. 2, pp. 208-222, 2010.

[14] M. Hu, C. O’Sullivan, R. R. Jardine, and M. Jiang, "Stressinduced anisotropy in sand under cyclic loading," Granular Matter, vol. 12, no. 5, pp. 469-476, 2010.

[15] Z. Shen, M. Jiang, and C. Thornton, "Shear strength of unsaturated granular soils: three-dimensional discrete element analyses," Granular Matter, vol. 18, no. 3, p. 37, 2016.

[16] A. Nardin and B. A. Schrefler, "Modelling of cutting tool-soil interaction-part II: macromechanical model and upscaling," Computational Mechanics, vol. 36, no. 5, pp. 343-359, 2005.

[17] N. Cho, C. D. Martin, and D. C. Sego, "A clumped particle model for rock," International Journal of Rock Mechanics and Mining Sciences, vol. 44, no. 7, pp. 997-1010, 2007.

[18] J.-W. Park and J.-J. Song, "Numerical simulation of a direct shear test on a rock joint using a bonded-particle model," International Journal of Rock Mechanics and Mining Sciences, vol. 46, no. 8, pp. 1315-1328, 2009.

[19] M. M. Sazzad and K. Suzuki, "Micromechanical behavior of granular materials with inherent anisotropy under cyclic loading using 2D DEM," Granular Matter, vol. 12, no. 6, pp. $597-605,2010$.

[20] C. O'Sullivan, L. Cui, and S. C. O'Neill, "Discrete element analysis of the response of granular materials during cyclic loading," Soils and Foundations, vol. 48, no. 4, pp. 511-530, 2008.

[21] B. Indraratna, P. K. Thakur, and J. S. Vinod, "Experimental and numerical study of railway ballast behavior under cyclic loading," International Journal of Geomechanics, vol. 10, no. 4, pp. 136-144, 2010.

[22] C. Chen, B. Indraratna, G. McDowell, and C. Rujikiatkamjorn, "Discrete element modelling of lateral displacement of a granular assembly under cyclic loading," Computers and Geotechnics, vol. 69, pp. 474-484, 2015.

[23] Y. Wang and Y.-L. Wang, "Liquefaction characteristics of gravelly soil under cyclic loading with constant strain amplitude by experimental and numerical investigations," Soil Dynamics and Earthquake Engineering, vol. 92, pp. 388-396, 2017.

[24] M. Jiang, A. Zhang, and T. Li, "Distinct element analysis of the microstructure evolution in granular soils under cyclic loading," Granular Matter, vol. 21, p. 39, 2019.

[25] JTG E40-2007, The Chinese Test Methods of Soils for Highway Engineering, China Communications Press, Beijing, China, 2007.

[26] JTG F10-2018, Technical Specifications for Roadbed Construction, China Communications Press, Beijing, China, 2018.

[27] GB/T 50123-2019, Standard for Geotechnical Testing Method, China Planning Press, Beijing, China, 2019.

[28] Z. M. He, Y. X. Liu, H. L. Tang et al., "Experimental study on cumulative plastic deformation of coarse-grained soil highgrade roadbed under long-term vehicle load," Advance in Civil Engineering, vol. 2018, p. 8, Article ID 8167205, 2018.

[29] Y. Lu and D. Frost, "Three-dimensional DEM modeling of triaxial compression of sands," Soil Behavior and GeoMicromechanics, pp. 220-226, American Society of Civil Engineers, Reston, VA, USA, 2010.

[30] W. M. Yan, "Fabric evolution in a numerical direct shear test," Computers and Geotechnics, vol. 36, no. 4, pp. 597-603, 2009.

[31] N. T. Ngo, B. Indraratna, and C. Rujikiatkamjorn, "Micromechanics-based investigation of fouled ballast using large- 
scale triaxial tests and discrete element modeling," Journal of Geotechnical and Geoenvironmental Engineering, vol. 143, no. 2, Article ID 04016089, 2017.

[32] M. B. Cil and K. A. Alshibli, "3D analysis of kinematic behavior of granular materials in triaxial testing using DEM with flexible membrane boundary," Acta Geotechnica, vol. 9, no. 2, pp. 287-298, 2014.

[33] G. Cheung and C. O'Sullivan, "Effective simulation of flexible lateral boundaries in two- and three-dimensional DEM simulations," Particuology, vol. 6, no. 6, pp. 483-500, 2008.

[34] N. Belheine, J. P. Plassiard, F. V. Donzé et al., "Numerical simulation of drained triaxial test using 3D discrete element modeling," Computers and Geotechnics, vol. 36, no. 1-2, pp. 320-331, 2009.

[35] C. Thornton, "Numerical simulations of deviatoric shear deformation of granular media," Géotechnique, vol. 50, no. 1, pp. 43-53, 2000.

[36] T. G. Sitharam, "Discrete element modelling of cyclic behaviour of granular materials," Geotechnical and Geological Engineering, vol. 21, no. 4, pp. 297-329, 2003.

[37] Z. Zhang, X. Zhang, H. Qiu et al., "Weighted average assembling method using in triaxial numerical experiment based on PFC3D," Journal of Wuhan University of Technology (Transportation Science \& Engineering), vol. 41, no. 2, pp. 263-267, 2017, in Chinese.

[38] J. Uzan, "Permanent deformation in flexible pavements," Journal of Transportation Engineering, vol. 130, no. 1, pp. 6-13, 2004.

[39] H. Y. He, "The field test and numerical analysis of expressway subgrade dynamic response," Journal of Changsha University of Science \& Technology (Natural Science), vol. 9, no. 2, pp. 13-18, 2012, in Chinese.

[40] C. Chazallon, P. Hornych, and S. Mouhoubi, "Elastoplastic model for the long-term behavior modeling of unbound granular materials in flexible pavements," International Journal of Geomechanics, vol. 6, no. 4, pp. 279-289, 2006.

[41] Y. Cai, Y. Chen, Z. Cao, H. Sun, and L. Guo, "Dynamic responses of a saturated poroelastic half-space generated by a moving truck on the uneven pavement," Soil Dynamics and Earthquake Engineering, vol. 69, pp. 172-181, 2015.

[42] NCHRP 1-28A, Harmonized Test Method for Laboratory Determination of Resilient Modulus for Flexible Pavement Design-Final Report, TRB, National Research Council, Washington, DC, USA, 2003.

[43] Z. H. Zhang, G. D. Zhang, X. L. Li et al., "The shear dilation and shear band of coarse grained soil based on discrete element method," Applied Mechanics and Materials, vol. 744, pp. 479-685, 2015.

[44] Y. Zhao and Z. Liu, "Numerical experiments on triaxial compression strength of soil-rock mixture," Advances in Civil Engineering, vol. 2019, Article ID 8763569, 15 pages, 2019.

[45] G. Q. Cai, S. P. Liu, J. Z. Song et al., "Insight into relationships between macroscopic and grain-scale parameters in calculating three-dimensional discrete element of unsaturated soils," Journal of Hunan University (Natural Sciences), vol. 45, no. S1, pp. 115-120, 2018, in Chinese.

[46] M. Jiang, H.-S. Yu, and S. Leroueil, "A simple and efficient approach to capturing bonding effect in naturally microstructured sands by discrete element method," International Journal for Numerical Methods in Engineering, vol. 69, no. 6, pp. 1158-1193, 2007. 